\title{
GARANTÍA DEL DERECHO A LA TUTELA JUDICIAL EFECTIVA EN LOS SISTEMAS PRINCIPALES DE RESOLUCIÓN DE CONFLICTOS ALTERNATIVOS: ARBITRAJE Y MEDIACIÓN
}

\author{
María Pérez-Ugena Coromina
}

\begin{abstract}
Sumario: 1. InTROdUCCIÓn. 2. Sistemas alternativos DE RESOlUCIÓN DE CONFLICTOS Y SU COMPATIBILIDAD CON EL DERECHO FUNDAMENTAL A LA TUTELA JUDICIAL EFECTIVA. 3. EL ORDEN PÚBLICO EN SU FUNCIÓN DE LÍMITE AL PRINCIPIO DISPOSITIVO EN LOS SISTEMAS ALTERNATIVOS DE RESOLUCIÓN DE CONFLICTO. 4. LA GARANTÍA DE LA TUTELA JUDICIAL EFECTIVA EN LOS PRINCIPIOS INFORMADORES DE LOS SISTEMAS DE ARBITRAJE Y MEDIACIÓN. 5. LA FUNCIÓN DEL PODER JUDICIAL COMO GARANTE Y EJECUTOR DE LAUdOS Y ACUERDOS DE MEDIACIÓN. 6. SÍNTESIS Y CONCLUSIONES.
\end{abstract}

\section{INTRODUCCIÓN}

El articulo 24 de la Constitución Española contiene un mandato dirigido al Poder Público para que garantice que las personas, en el ejercicio de sus derechos e intereses legítimos, obtengan de los Jueces y Tribunales una tutela judicial efectiva. La realidad evidencia la existencia y cada vez mayor desarrollo de los sistemas alternativos de resolución de conflictos al margen del procedimiento ordinario de actuación de Jueces y Tribunales. Si las partes en un conflicto deciden voluntariamente, en uso de su libertad, renunciar al derecho de someter a la actividad jurisdiccional de jueces y tribunales la controversia que les afecte en ejercicio del derecho recogido en el artículo 24 $\mathrm{CE}$, y someterla a alguno de los sistema alternativos mencionados, esta renuncia no debe conllevar a una situación real de indefensión.

$\mathrm{El}$ artículo $117 \mathrm{CE}$ al señalar que «el ejercicio de la potestad jurisdiccional en todo tipo de procesos, juzgando y haciendo ejecutar lo juzgado, co- 
rresponde exclusivamente a los Juzgados y Tribunales determinados por las leyes, según las normas de competencia y procedimiento que las mismas establezcan» recoge un principio de unidad jurisdiccional y crea una reserva de jurisdicción que supone que ninguna otra autoridad distinta de los juzgados y tribunales tiene potestad jurisdiccional.

En la actualidad, ya ningún sector doctrinal sostiene que ese precepto constitucional implica la imposibilidad de existencia de sistemas alternativos no estrictamente jurisdiccionales de resolución de conflictos. Una interpretación semejante no es asumible actualmente, no solo porque en el caso mas evidente del arbitraje responde a una clara tradición histórica y forma parte de nuestras instituciones con soporte normativo en plano de Ley Ordinaria, sino porque, además, vivimos en un mundo global en el que estos sistemas -en adelante ADRs- están plenamente aceptados como instrumentos de resolución de conflictos en el ámbito internacional ${ }^{1}$.

No hay, por tanto, contradicción entre un procedimiento de solución extrajudicial de conflictos y el derecho a la tutela judicial efectiva junto con el carácter exclusivo de la función jurisdiccional de jueces y Tribunales, de la misma forma que no se oponen un proceso público de realización de justicia con un procedimiento que tenga su base en el derecho a la libre disposición de las partes ${ }^{2}$. El tema capital, sin embargo, reside en delimitar qué tipo de actuación corresponde a los Jueces y Tribunales cuando los particulares han decidido la utilización de un ADR en la solución de sus conflictos, asumiendo que el árbitro o mediador no son sujetos que ejerzan un mandato jurisdiccional ni forman parte institucional del Estado.

Sentado lo anterior, lo que pretendemos es analizar en qué forma el poder público está obligado a hacer cumplir las garantías propias de la tutela judi-

${ }^{1}$ Las normas internacionales ratificadas por España han sido un impulso fundamental en el reconocimiento del arbitraje, así el Convenio de Ginebra sobre el Reconocimiento y Ejecución de Sentencias Arbitrales, ratificado en 1930 o la Convención de Nueva York de 1958 sobre Reconocimiento y Ejecución de Sentencias Arbitrales Extranjeras ratificado en 1977 y el Convenio de Ginebra de 1961 sobre Arbitraje Comercial Internacional. Respecto de la mediación, en el ámbito europeo la aprobación de la Directiva 2008/52/CE, del Parlamento Europeo y del Consejo, de 21 de mayo de 2008 ha supuesto un impulso fundamental (DOL núm 136, de 24 de mayo). Está basada en el Libro Verde sobre las modalidades alternativas de solución de conflictos en el ámbito del derecho civil y mercantil fue elaborado por la Comisión Europea en el mes de abril de 2002. disponible en: http://eur-lex.europa.eu/LexUriServ/site/es/com/2002/com2002_0196es01.pdf. La Recomendación (86) 12 del Consejo de Ministros a los Estados miembros del Consejo de Europa respecto a medidas para prevenir y reducir la carga de trabajo excesiva en los Tribunales, recomendaba promover la solución amistosa de los conflictos (Adoptada por el Consejo de Ministros de 16 de septiembre de 1986, durante la 39a reunión de los Delegados de los Ministros).

${ }^{2}$ En este sentido el TC se ha manifestado claramente al señalar que el arbitraje es compatible con la Constitución en varias ocasiones despejando cualquier posible duda al respecto (SSTC 43/1988; 233/1988 y 288/1993, entre otras). 
cial efectiva en los sistemas alternativos de resolución de conflictos. Se trata por tanto, de determinar el papel del Estado como garante de los derechos fundamentales en los casos en que la Justicia no se administre directamente por los órganos del Poder Judicial, sino que lo haga con el auxilio de sistemas alternativos de resolución de conflictos.

En conclusión, entendemos que la función del Estado en este ámbito no es solo ofrecer un sistema de Justicia que permita una tutela efectiva. También es función del Estado, en desarrollo del artículo 9.2 de la Constitución promover la libertad de forma real y efectiva. Lo que en relación al tema que nos ocupa supone permitir y favorecer que de la propia sociedad emerjan instituciones alternativas, que, dando cumplimiento a los principios del artículo 24 de la Constitución, permitan una conexión entre ámbitos público y privado en la capacidad de resolver conflictos, siempre que se cumplan las garantías constitucionales. Porque tengamos en cuenta que arbitraje y mediación son instituciones ${ }^{3}$ fundamentadas en la voluntad de las partes, pese a que por su complejidad no podamos decir que tal naturaleza sea exclusivamente privada frente al carácter público del proceso judicial.

Los sistemas ADRs son básicamente la mediación, el arbitraje, la negociación y la conciliación. Nos centraremos en el presente trabajo en el arbitraje y la mediación por ser los dos sistemas principales que representan a los dos tipos de mecanismos de resolución de conflictos, heterocompositivo y autocompositivo, si bien existen otros mecanismos autocompositivos de ADRs, principalmente la negociación y conciliación ${ }^{4}$.

3 Tanto el arbitraje como la mediación son instituciones en el sentido señalado por Merino Merchán JF y Chillón medina, J.m. Tratado de Derecho Arbitral. Civitas 2006., págs 214 y ss. como conjunto de actividades relacionadas entre sí por el vínculo de una idea común y objetiva a la que figuran adheridas diversas voluntades particulares. En este caso la vinculación se produce por el acuerdo o convenio por el que se busca una solución al margen de los mecanismos judiciales del Estado.

${ }^{4}$ En España, el procedimiento de conciliación está reconocido tanto en los procedimientos laborales como en los civiles, siendo en ambos casos un procedimiento previo al inicio del proceso judicial. La normativa aplicable es la Ley de Enjuiciamiento civil de 1881 (art. 460 a 480) y la Ley 36/2011, de 10 de octubre, reguladora de la jurisdicción social. En la conciliación las partes acuden a un tercero, pudiendo ser éste un órgano judicial, a los efectos de alcanzar una solución a un conflicto existente, evitando acudir a un procedimiento judicial. El tercero no incita activamente a las partes a alcanzar el acuerdo al conflicto suscitado, consistiendo su función más bien en reunir a las partes y en transmitir entre ellas los mensajes o las informaciones en forma correcta, con la finalidad de que las partes alcancen el acuerdo entre ellas, pero sin que se adopten por parte del tercero medidas persuasivas, integradoras e incluso de carácter disuasorio que tiendan a concretar y posibilitar una solución de consenso entre las partes. Pese a señalar tales diferencias entre conciliación y negociación, reconocemos que éstas son imprecisas.

La negociación: Es un método por el cual las partes interesadas resuelven conflictos, procurando obtener resultados que sirvan a sus intereses. Se contempla generalmente 


\section{SISTEMAS ALTERNATIVOS DE RESOLUCIÓN DE CONFLICTOS Y SU COMPATIBILIDAD CON EL DERECHO FUNDAMENTAL A LA TUTELA JUDICIAL EFECTIVA}

El arbitraje y la mediación se presentan como instrumentos de solución de conflictos con características que les diferencian de modo nítido, si bien comparten su naturaleza extrajudicial. Ambos sistemas derivan de la voluntad de las partes, pero no son inmunes al control del Estado ${ }^{5}$ Y ello porque el derecho a la tutela judicial efectiva trasciende el ámbito exclusivamente judicial. La cuestión es, por tanto, determinar los límites y efectos del control que ejerce el Poder Judicial en relación a ambos procedimientos, de tal forma que, respetando la libertad de las partes, se proteja el derecho que les asiste a la tutela judicial efectiva.

$\mathrm{El}$ arbitraje es un procedimiento heterocompositivo en el que se faculta a un tercero para la resolución del conflicto, frente a la mediación en el que la resolución de contiendas es de tipo autocompositivo, por el que las partes las resuelven directamente con el auxilio de un tercero.

El juez, el árbitro y el mediador son copartícipes de la Administración de Justicia desde posiciones muy diferentes. El juez desde el ejercicio de la función jurisdiccional a través de una función pública. El árbitro fundamentándose en la libertad de las partes, que le otorgan el poder para decidir sobre una controversia, y en el caso del mediador de forma mas indirecta pero también con fundamento en la voluntad de las partes, puesto que son éstas las que gracias a la ayuda del mediador decidirán sobre la resolución de sus conflictos quedando después obligadas por dicha decisión o acuerdo.

\subsection{Arbitraje}

El arbitraje puede ser definido como un mecanismo extrajudicial para la resolución de conflictos, en el que las partes deciden someterse a un tercero o terceros para la resolución de la controversia existente. Se trata de un sistema heterocompositivo cuyo fundamento está en la capacidad de disposición de las partes para aceptar previamente la decisión que se tome en el procedimiento arbitral.

como una forma de resolución alternativa de conflictos o situaciones que impliquen acción multilateral. son las partes las encargadas de buscar una solución al conflicto existente, sin acudir a un tercero que sea quien resuelva el citado conflicto.

5 Barona Vilar, S. (2004). pp. 47 y ss. señala como hay países en los que se ha pretendido un tratamiento integral de soluciones heterocompositivas y autocompositivas. Así por ejemplo la Arbitation and Conciliation Law in India, Act 1996. Ley N 727 de Arbitraje, Mediación y Conciliación de Bolivia de 1997. Así como las regulaciones de Bolivia y Panamá. 
Estamos ante una institución con arraigo histórico, que en su forma más primitiva arranca del Derecho Romano y se recoge en las Partidas y la Nueva y Novísima Recopilación y que tuvo un reconocimiento expreso en la Constitución de 1812, en la que se conceptúa como un procedimiento alternativo ${ }^{6}$. Sin embargo, desde que esta institución se desarrolló a través de una ley específica, con la Ley de $1953^{7}$, ha sido tratada con recelo y sometida a fuertes restricciones hasta $1988^{8}$.

El cambio mas reciente en el tratamiento del arbitraje se produce con la Ley de 60/2003 ${ }^{9}$ si bien la Ley de 1988 ya había dado pasos decisivos basados en la libertad individual como fundamento de la institución arbitral, a la que considera un forma paralela que sustituye a la acción del Poder Judicial del Estado ${ }^{10}$, aunque esta caracterización no debe llevarnos a entender que en el arbitraje se esconde una renuncia excepcional del derecho a la tutela judicial efectiva que, con carácter general, recae exclusivamente en jueces y Tribunales. Si atribuyéramos tal carácter excepcional al arbitraje, debería ser interpretado de manera restrictiva, frente a la interpretación mas abierta, y que tiene su arraigo en el derecho constitucional español, en las Cortes de Cádiz, soportando una concepción favorable al arbitraje ${ }^{11}$.

Los elementos que diferencian el arbitraje de un proceso judicial, son, sustancialmente, los siguientes: el arbitraje tiene una base contractual privada, en tanto que el proceso judicial es instrumento estatal y por tanto público; en el arbitraje la persona o personas encargadas de decidir sobre la controversia -árbitros-son elegidas por las partes, frente a los jueces que son nombrados por el Estado; los jueces están investidos de potestas por ser órganos estatales mientras que los árbitros pueden tener auctoritas pero no potestas.

${ }^{6}$ En su artículo 280 la Constitución gaditana reconoce el derecho de los españoles a a terminar sus diferencias por medio de jueces árbitros elegidos por ambas partes y en el 281 reconoce la fuerza ejecutiva de las decisiones de los árbitros.

7 De hecho en la práctica el arbitraje estaba sometido a fuertes condicionantes, limitaciones en cuanto a las materias disponibles y un procedimiento complejo que dificultaba el arbitraje interno y excluía el arbitraje internacional.

${ }^{8}$ Merchán Alvarez, J. El arbitraje, Estudio Histórico Jurídico. Ed. Universidad de Sevilla. 1981.

9 Esta Ley está inspirada en el nuevo marco de la Ley Modelo elaborada por la Comisión de las Naciones Unidas para el Derecho Mercantil Internacional de 1985.

${ }^{10}$ En España la figura del arbitraje se encuentra regulada en la Ley 60/2003, de 23 de diciembre, de Arbitraje y en la Ley 11/2011, de 20 de mayo, de reforma de la Ley 60/2003, de 23 de diciembre, de Arbitraje y de regulación del arbitraje institucional en la Administración General del Estado. La citada normativa será de aplicación a los arbitrajes cuyo lugar se halle dentro del territorio español, ya sean de carácter interno o internacional, sin perjuicio de lo establecido en tratados de los que España sea parte o en Leyes que contengan disposiciones especiales sobre arbitraje.

11 Vid. Martín Muñoz, A y Hierro Anibarro S. Comentario a la Ley de arbitraje. Marcial Pons, 2006, pp. 38 y ss. 
Por último, el laudo es un equivalente jurisdiccional, equiparable a una resolución judicial en cuanto que produce efectos de cosa juzgada, pero su cumplimiento coactivo trasciende los poderes del árbitro y solo puede conseguirse mediante la actuación del Poder Judicial, que monopoliza el poder de ejecución forzosa ${ }^{12}$.

Lo que verdaderamente caracteriza y define al arbitraje es la noción, antes expresada, de equivalente jurisdiccional ${ }^{13}$. Además, hay que añadir otras cuestiones, que afectan al objeto del arbitraje, a la controversia, y al proceso de solución. En primer término, es decisivo que el objeto de la controversia sea arbitrable. El arbitraje puede versar sobre todas aquellas materias que sean de libre disposición para las partes, conforme a la normativa vigente en la que se concretan limitaciones legales de materias que no son disponibles, por lo que necesariamente se deben reconducir para su solución al Proceso Judicial en sentido estricto ${ }^{14}$.

En este punto de la arbitrabilidad de la materia, conviene señalar que el arbitraje se presente normalmente con la característica de ser un procedimiento especializado. Una de las finalidades del arbitraje reside en que las partes puedan acudir a terceros especializados en la materia sobre la que verse la controversia, para de este modo garantizarse una mejor y mas clara solución al conflicto que las separa. La complejidad del mundo económico y jurídico actual reclama un indispensable proceso de especialización, que no solo se vislumbre en los ARDs sino, además, en el seno del propio Poder Judicial, aunque en este último, por su propia naturaleza, la especialización

12 GuZman Fluja, v. «Notificaciones, comunicaciones y cómputo de plazo» págs 190 y ss. «Intervención judicial» pp. 242 y ss. Ambos en Comentarios a la Ley de arbitraje. (Ley 60/2003) BARONA Vilar, S. (coord) Thomson-Civitas 2004, pp. 242 y ss.

${ }_{13}$ Para ello es necesario que se den las siguientes condiciones: Que el instituto arbitral esté regulado en una Ley formal votada en Cortes Generales debiendo tener esta norma carácter estatal por tratarse de una materia sobre la que el Estado tiene competencia exclusiva de acuerdo con el artículo 149.1.6 y 9 de la Constitución (SSTC 15/1989 y 62/1991); que se genere por un sometimiento libre y voluntario, de modo que la voluntariedad del convenio arbitral aparezca sin sombra o penumbra alguna sobre la libertad de aceptación y sumisión al mismo por las partes, de manera que no haga resentirse el derecho fundamental a la tutela judicial efectiva del artículo 24.1 (SSTC 11/1981, 2112/1991, 2386/1995, 174/1995); que una vez aceptado voluntariamente el convenio por las partes, el arbitraje desplace con todas sus consecuencias al proceso y al recurso ordinario (art. 63 y siguientes de la LEC); que las partes, además de dar un trato preferente a la autonomía de la voluntad sobre el modelo jurisdiccional preestablecido legalmente, aceptan asumir el laudo firme con efectos idénticos a la cosa juzgada, Vid. Merino Merchan, J.F y Chillón J.M. ob cit. pp. 64-65.

${ }^{14}$ La ley 43/2006 parte de una presunción general de disponibilidad y entiende que la inseparabilidad no rige al objeto de determinar las materias disponibles para el arbitraje, frente a la ambigua Ley de 1988 que entendía como no disponibles «las materias inseparablemente unidas a otras sobre las que las partes no tengan poder de disposición». 
quizás no llegue a disponer de la misma profundidad que pueda darse en los restantes medios de solución de conflictos.

En lo que se refiere a los árbitros, las partes tienen capacidad para decidir quién es el árbitro o árbitros, o a través de qué procedimiento se van a designar a los mismos dentro de los límites que establece la ley y que van dirigidos a garantizar los principios informadores del procedimiento. En un procedimiento arbitral puede haber uno o varios árbitros, siempre impares, siendo la imparidad un requisito esencial de composición del órgano arbitral ${ }^{15}$, que serán personas físicas, no jurídicas, y que deben estar en pleno ejercicio de sus derechos civiles, entendiendo por tales ser mayor de edad y con plena capacidad de obrar ${ }^{16}$.

Se exige además que los árbitros sean y permanezcan durante el arbitraje independientes e imparciales ${ }^{17}$, sin que puedan mantener con las partes relación personal, profesional o comercial ${ }^{18}$, estableciendo la Ley la obligatoria revelación de todas las circunstancias que puedan dar lugar a dudas sobre su

15 Vid Gonzalez Malabia, «Número de árbitros», «Capacidad para ser árbitros», «Arbitraje institucional», «Nombramiento de los árbitros» $\mathrm{y}$ «Aceptación de los árbitros» en Comentarios a la Ley de arbitraje. (Ley 60/2003) BARONA VILAR, S. (coord) ThomsonCivitas 2004. Pp. 519 y ss.. Se trata de una nueva redacción con la Ley de 2003 que pretende agilizar y abaratar el procedimiento arbitral.

16 JimeneZ DE PARGA, J. «Sistemas de nombramiento de árbitros», en MERCHA, J.F. Curso de derecho arbitral. Tirant Lo Blanch, Valencia 2009, pp. 137 y ss. Entiende que cabrían otras interpretaciones jurídicas pero que en definitiva se trata de determinar qué requisitos de capacidad debe reunir la persona llamada a resolver un litigio. LEON SANZ, F.J. en Comentarios a la ley de arbitraje. PÉREz-LlorCA, Aranzadi, 2005. pp. 119 y ss. señala que la expresión ejercicio pleno de los derechos civiles resulta equivalente a la de plena capacidad para obligarse. GonZALEZ MALABIA ob cit págs 519 y ss. Nos remite a las normas del código civil. Supone la mayoría de edad, no estar incapacitado judicialmente, no estar declarado pródigo y no estar declarado como quebrado o concursado».

17 Como nos recuerda Alonso Puig, J. M. Ser independiente e imparcial no es lo mismo que no incurrir en ninguna de las causas de abstención y recusación de jueces y magistrados. Así la Exposición de Motivos de la Ley de arbitraje señala que hay que entender que los motivos de abstención y recusación de jueces y magistrados no son siempre adecuados en materia de arbitraje. «Motivos de abstención y recusación» en Comentarios a la nueva ley de arbitraje, GonZÁle soriA, J. . (coord) Aranzadi, 2011 pp. 237 y ss. Montero Aroca. J «Motivos de abstención y recusación» en Comentarios a la Ley de arbitraje. BARONA VILAR, s.(coord) Thomson-Civitas 2004.. pp. 659 y ss. Sobre la independencia e imparcialidad, se trata de dos cuestiones distintas aunque a veces se traten como si fueran un único concepto. Si la independencia tiene un carácter absoluto, la imparcialidad es relativa y debe atender a un proceso concreto. A efectos de arbitraje, la norma se refiere en realidad a imparcialidad puesto que el árbitro carece de estatuto propio, de ahí que no pueda cuestionarse su independencia.

18 Alonso Puig, J. M. Alonso Puig, J. M. ob cit. pp. 237 y ss. entiende que esta referencia de la Ley es poco afortunada no debe dársele mas alcance de el que permita la voluntad común de las partes y el principio de igualdad imperativo. 
imparcialidad, así como las figuras de la abstención y recusación ${ }^{19}$, remoción y renuncia ${ }^{20}$.

La vulneración del principio de igualdad en el nombramiento del árbitro supone la nulidad del convenio arbitral en ese punto. Los órganos judiciales, en la resolución de un posterior proceso de anulación del laudo decidirán si se ha conculcado la ley en este punto específico por haberse dictado en circunstancias abusivas ${ }^{21}$.

En relación al nombramiento de árbitro, se considera que se ha vulnerado el principio de igualdad, entre otras circunstancias, si una de las partes impusiera el procedimiento de designación sin concurrir la voluntad conforme de la parte contraria o en los casos en que se determina un procedimiento en el que una de las partes tuviera que designar un número superior de árbitros de aquel que le correspondería designar o si la designación del árbitro o de la mayoría de los árbitros se realiza por una sola de las partes ${ }^{22}$.

Hay ademas una previsión legal de que los órganos judiciales participen y auxilien en el procedimiento arbitral a las partes en el nombramiento de los árbitros. Nos referimos a los casos de procesos supletorios que pueden darse, en los que la actuación judicial tiene un carácter subsidiario, bien cuando las partes no hayan acordado un procedimiento para la designación en el convenio o en un momento posterior, o bien cuando a pesar de existir un pacto al respecto no hay acuerdo entre las partes o no es posible designar a los árbitros según el procedimiento previsto. En estos casos, cualquiera de las partes puede solicitar la intervención del tribunal competente para el nombramiento de los árbitros.

Asimismo es preciso que el procedimiento de arbitraje se tramite conforme a los principios que señala la Ley, con las garantías de igualdad de las partes, audiencia, contradicción y prueba. Aunque la voluntariedad es elemento esencial al arbitraje, y por ello el Tribunal Constitucional ha entendido que no son procedimientos arbitrales los de carácter público obligatorio por no contar con el elemento de voluntariedad ${ }^{23}$, eso no quiere decir que no exista un mínimo contenido procedimental en la solución arbitral. En este

19 Montero Aroca. J ob cit. pp. 659 y ss.

${ }^{20}$ Sobre los supuestos de imposibilidad o falta de ejercicio de funciones, vid MARTíNEZ GARCÍA. E. «Falta o imposibilidad del ejercicio de las funciones» y «nombramiento de árbitro sustituto» en Comentarios a la Ley de arbitraje. (Ley 60/2003) BARONA VILAR, S.(coord) Thomson-Civitas 2004, págs 694 y ss. pp. 694 y ss.

${ }^{21}$ Vid STC 9/2005 sobre imparcialidad del árbitro y acción de anulación del proceso. El artículo 41.1 de la Ley de arbitraje señala como motivo de anulación «que la designación de los árbitros o el procedimiento arbitral no se han ajustado al acuerdo entre las partes, salvo que dicho acuerdo fuera contrario a una norma imperativa de esta Ley o a falta de dicho acuerdo, que no se han ajustado a esta Ley».

22 Vid Gonzalez Malabia. o $b$ cit. pp. 519 y ss.

${ }^{23}$ STC 56/90. 
punto la evolución normativa ha sido muy clara y relevante, porque la Ley de 1953 se manifestó rígida y formalista en lo que al procedimiento se refiere, mientras que la de 1988, al edificar todo el instituto sobre la autonomía de la voluntad, descarga al arbitraje de buena parte del formalismo anterior, tanto para declarar la eficacia del convenio arbitral como en lo referente al procedimiento en si mismo considerado ${ }^{24}$, permitiéndose a las partes modificaciones en la tramitación del procedimiento arbitral ${ }^{25}$.

Concluimos señalando que el arbitraje está sometido al control propio de un Estado de derecho, que tal control está limitado como consecuencia del fundamento del arbitraje en la autonomía de la voluntad y que, como veremos, deberá ser ejercido por medio de juez predeterminado según los motivos tasados en la Ley 46/2003. Sin embargo no cabe el control mediante el recurso de amparo por vulneración del contenido del artículo $24 \mathrm{CE}$ ante el Tribunal Constitucional ${ }^{26}$.

\subsection{Mediación $^{27}$}

La mediación tiene como ejes centrales de su actividad la voluntariedad y libre decisión de las partes y se desarrolla a partir de la intervención de un profesional neutral que facilita la resolución del conflicto por las propias partes, de una forma equitativa, permitiendo el mantenimiento de las relaciones subyacentes y conservando el control sobre el final del conflicto, que

${ }^{24}$ El espíritu no normativo de la Ley se inspira en normas como el Convenio de Arbitraje Comercial de 1961,el Convenio de Nueva York de 1958 y el Reglamento de Arbitraje Comercial Internacional de la Comisión de las Naciones Unidas para el Derecho Mercantil Internacional (UNCITRAL).

${ }^{25}$ Vid Martinez González. P. El nuevo régimen de arbitraje Bosch, 2011.. pp. 87 y ss. Además de señalar la flexibilidad como característica que distingue el arbitraje del proceso, este autor se refiere a estas otras: el idioma, el lugar de las actuaciones, la práctica de la prueba, la designación de árbitro y el abandono del proceso judicial comenzado. La nueva Ley de 2003 da un paso mas y reconoce, además, la validez al uso de nuevos medios de comunicación y nuevas tecnologías, tanto para la presentación de documentos como para la realización de comunicaciones entre las partes y el arbitro, favoreciendo de esta forma la agilidad del procedimiento, Montesinos García, A. Arbitraje y nuevas tecnología. Civitas, 2007. PÉREZ-UGEnA, M. «Arbitraje telemático» en MERCHAN, JF. (coord). Curso de derecho arbitral. Tirant Lo Blanch, Valencia 2009. pp. 385 y ss.

${ }_{26}$ No es un acto apto de ser recurrido porque no se refiere a ningún poder público por lo que resulta extraño al ámbito y función del recurso de amparo ante el TC (STC 13/1997). Sin embargo sí se puede ejercer el control del TC en cuanto a los actos del Poder judicial en actuaciones judiciales en relación con el procedimiento.

27 Guillén Gestoso, C.; J. Mena Clares; E. Ramos Ruiz y S. Sánchez Sevilla, «Aproximación genérica a la mediación», SANCHEZ Perez, J.(coord)., Aproximación interdisciplinar al conflicto y a la negociación, Cádiz: Servicio de Publicaciones de la Universidad de Cádiz, 2005. p. 59-72. 
queda expresado en el acuerdo de mediación ${ }^{28,29,30}$. Se trata, de una forma autocompositiva o no adversarial frente a la vía heterocompositiva o adversarial, que es la propia del arbitraje. Esta diferenciación es fundamental y sitúa a la mediación como una forma de gestión positiva de un conflicto a través de técnicas multidisciplinares.

En su origen, como sistema de resolución de conflictos, forma parte de la historia de la humanidad. Podemos ligarlo a la idea de renuncia a la violencia en beneficio de la comunidad y a la tradición humanística centroeuropea de finales del Renacimiento, que adoptó el diálogo como forma básica de la argumentación racional y del juicio ${ }^{31}$.

La aprobación de la Directiva 2008/52/CE, del Parlamento Europeo y del Consejo, de 21 de mayo de 2008, sobre determinados aspectos de la mediación en asuntos civiles y mercantiles, ha supuesto un impulso fundamental ${ }^{32}$. En la citada Directiva se señala que la utilidad de ampliar el recurso a la mediación la constituyen esencialmente las ventajas del propio mecanismo de solución de litigios: una manera más rápida, simple y rentable de solucionar conflictos que permite tener en cuenta más aspectos, mas aristas y perfiles de los intereses de las partes. Ello aumenta las posibilidades de alcanzar un

${ }^{28}$ En España, la institución de la Mediación derivada de la promulgación de la Ley 5/2012 de 6 de julio de Mediación para asuntos civiles y mercantiles, como sistema alternativo para la resolución de conflictos.

${ }^{29}$ Directiva 2008/52/CE, del Parlamento Europeo y del Consejo, de 21 de mayo de 2008, sobre determinados aspectos de la mediación en asuntos civiles y mercantiles, define en su artículo 3 lo que se entiende por mediación: «un procedimiento estructurado, sea cual sea su nombre o denominación, en el que dos o más partes en un litigio intentan voluntariamente alcanzar por sí mismas un acuerdo sobre la resolución de su litigio con la ayuda de un mediador. Este procedimiento puede ser iniciado por las partes, sugerido $u$ ordenado por un órgano jurisdiccional o prescrito por el Derecho de un Estado miembro». Entre otros puede verse sobre el tema: ORDOÑEZ SOLOS, D. «La Directiva sobre mediación y sus efectos en el derecho español: fuera de los tribunales también hay justicia», Diario La Ley, núm. 7165, 2009, pp. 1-30.

30 Además, la mediación puede cumplir con otras funciones. Específicamente, puede hablarse de (i) funciones de carácter preventivo. La mediación permite conocer el estado de la conflictividad social y deviene, en sí misma, una herramienta de prevención»; (ii) de carácter educativo y (iii) de carácter reparador. se sitúa en el ámbito penal (y en el marco de la restorative justice), donde la mediación busca una actividad restauradora o de conciliación con la víctima por parte del menor. Libro Blanco de Mediación. págs 836 y ss. Puede verse en: http://www20.gencat.cat/docs/Justicia/Documents/Publicacions/llibres\%20fora\%20colleccio/Libro_blanco_mediacion.pdf obtenido en mayo 2014.

${ }^{31}$ Libro Blanco de la Mediación, ob cit. pp. 107.

32 Esta Directiva está basada en el Libro Verde sobre las modalidades alternativas de solución de conflictos en el ámbito del derecho civil y mercantil fue elaborado por la Comisión Europea en el mes de abril de 2002. disponible en: http://eur-lex.europa.eu/ LexUriServ/site/es/com/2002/com2002_0196es01.pdf 
acuerdo que respetarán voluntariamente, y contribuye a preservar una relación amistosa y sostenible entre ellos ${ }^{33}$.

En nuestro País, en desarrollo de la citada Directiva, se aprueba la Ley de Mediación en la que «se entiende por mediación aquel medio de solución de controversias, cualquiera que sea su denominación, en que dos o más partes intentan voluntariamente alcanzar por si mismas un acuerdo con la intervención de un mediador $\rangle^{34}$.

El sistema de mediación se basa en determinados principios, sustancialmente la voluntariedad y libre disposición de la materia, y los de imparcialidad, neutralidad y confidencialidad ${ }^{35}$. A estos principios se añaden las reglas o directrices que han de guiar la actuación de las partes en la mediación, como son la buena fe y el respeto mutuo, así como su deber de colaboración y apoyo al mediador ${ }^{36}$.

Al tratarse de un sistema autocompositivo, son las partes implicadas en la mediación las que han de encontrar una solución a su conflicto, no delegando en una tercera persona la decisión sobre el mismo. Por ello mismo, el mediador debe mantenerse en un plano neutral, imparcial y equidistante entre las partes. Es un mero canal de la comunicación que debe ayudar a las partes a negociar y alcanzar ellas una solución ${ }^{37}$.

Las partes son, por tanto, los protagonistas del desarrollo de la mediación y su voluntad o autonomía de decisión, el principio eje de todo el procedimiento, de tal forma que el mediador queda obligado a la búsqueda de soluciones, a

${ }^{33}$ La Directiva ha venido a completar otras regulaciones en ámbitos diferentes. Entre ellas, la Decisión-Marco 2001/220/JAI, de 15.3.2001, sobre la implantación de la mediación en la vía penal, así como varias Recomendaciones del Consejo de Europa a los estados miembros en derecho de familia (R1/1998) y en derecho penal (R19/1999).

${ }^{34}$ En cuanto a su regulación destaca la reciente Ley 5/2012 de 6 de julio, de mediación en asuntos civiles y mercantiles, publicada en el BOE de fecha 7 de julio de 2012. Junto con éstas, también de ámbito nacional, debemos tener en cuenta: Ley 1/2000 de 7 de enero, de Enjuiciamiento Civil, con la redacción dada con los artículos modificados por la Ley 5/2012 de 6 de julio, de mediación en asuntos civiles y mercantiles. Así como la Ley de la Jurisdicción Social. Artículos 63 a 68. En el ámbito de la Unión Europea, tenemos la Directiva 2008/52/CE. Y de ámbito autonómico las leyes en materia de mediación familiar.

${ }^{35}$ Sobre esta cuestión vid. BARONA S. Mediación en asuntos civiles y mercantiles en España. Tirant Lo Blanch. 2013, pp. 180 y ss.

${ }_{36}$ En la mediación el eje cardinal del sistema es la figura del mediador. Los principios rectores de su actuación. Libertad de las partes en conflicto y del mediador para participar en los procedimientos de mediación, igualdad de las partes, imparcialidad, neutralidad, principio de legalidad, deber de no imposición, confidencialidad, protección del bienestar e interés del menor y personas con discapacidad, competencia y ética del mediador, buena fe de las partes en conflicto y del mediador, sencillez y rapidez del procedimiento y otros que, junto con los deberes del mediador familiar en el ejercicio de su profesión, perfilan una actuación reglada de la mediación.

37 Guillén Gestoso, C.; Mena Clares, J.; Ramos Ruiz, E. y Sánchez Sevilla, S. ob cit pp. 59-72. 
trazar puentes de comunicación e intentar que las partes lleguen a un acuerdo desde una posición neutral y sin que en ningún momento, al contrario de lo que ocurre con el arbitraje, pueda variar su función imponiendo soluciones, sino que el proceso gira en torno al acuerdo y capacidad de disposición de las partes.

En lo que se refiere a los mediadores, la Ley regula de forma detenida las cuestiones relacionadas con su necesaria preparación, condiciones de ejercicio y demás aspectos que vienen a reforzar la exigencia de imparcialidad del mediador a lo largo del procedimiento ${ }^{38}$.

Se trata, por último, de un procedimiento complementario a la jurisdicción, no antagónico ni excluyente de la misma; extrajudicial, por el hecho de que se administra por sujetos no integrados en el Poder Judicial y alternativo, por cuanto no permite la utilización simultánea de la resolución judicial ${ }^{39}$.

\section{EL ORDEN PÚBLICO EN SU FUNCIÓN DE LÍMITE AL PRINCIPIO DISPOSITIVO EN LOS SISTEMAS ALTERNATIVOS DE RESOLUCIÓN DE CONFLICTO}

Hemos señalado ya que el fundamento de los sistemas de ADRs descansa en el principio dispositivo, que tiene su base en la libertad como valor superior del ordenamiento jurídico y como derecho fundamental ${ }^{40}$. La libertad de las partes se resume en la posibilidad inicial de elegir qué tipo de procedimiento utilizan para resolver sus controversias y en la de cómo se desarrolla. Sin embargo, no estamos ante una libertad absoluta sino que la autonomía de las partes viene limitada por el orden público. La noción de orden público, que es difusa y cuyo contenido varía en función de distintos criterios, se constituye en un límite impreciso, pero efectivo, al poder de decisión de las partes en conflicto.

En el ámbito de los sistemas de ADRs hay una tendencia a limitar o confundir el concepto amplio de orden público con el mas limitado de orden público procesal, es decir, referirlo en exclusiva a ciertos principios de naturaleza procedimental, como audiencia o igualdad de partes, que son propios del proceso judicial. Sin embargo, el orden público debe entenderse también, y de manera muy sustancial, relacionado con los derechos fundamentales y libertades públicas que garantiza la Constitución. Podemos sostener que la vulneración del orden público no se equipara con una infracción de una norma imperativa sino con la vulneración de un principio constitucional.

En desarrollo del principio dispositivo en los ADRs, el artículo 19 de la LEC establece:

${ }^{38}$ BARONA, S. Mediación... ob cit. pp. 180 y ss.

${ }^{39}$ Seguimos en este punto a MarTín Diz, F. La Mediación: Sistema complementario de la Administración de Justicia. CGPJ. 2010.

40 Así lo ha señalado el TC en STC 75/96 «La autonomía de la voluntad de las partes constituye la esencia y el fundamento de la institución arbitral, por cuanto que el arbitraje conlleva la exclusión de la vía judicial» 
«Los litigantes están facultados para disponer del objeto del juicio y podrán renunciar, desistir del juicio, allanarse, someterse a mediación o a arbitraje y transigir sobre lo que sea objeto del mismo, excepto cuando la ley lo prohiba o establezca limitaciones por razones de interés general o en beneficio de tercero».

El principio dispositivo, como soporte legitimador del arbitraje, provoca que resulten nulos los denominados arbitrajes públicos obligatorios porque, como ha señalado el TC en STC 56/90, se carece del elemento de voluntariedad o éste se encuentra diluido en términos tales que no permiten apreciar un consentimiento expresamente manifestado de aceptar el convenio.

En el contexto de la ley de arbitraje 60/2003, tanto las reglas del proce$\mathrm{so}^{41}$, el nombramiento de los árbitros o la elección de normas ${ }^{4243}$ se fundamentan en el principio dispositivo.

En el caso de la mediación, son las partes las que libremente deciden acudir a un sistema de mediación para poner fin a una controversia existente. Este principio también se encuentra consagrado en la Directiva 2008/52/CE del Parlamento Europeo y del Consejo, sobre ciertos aspectos de la mediación en asuntos civiles y mercantiles de 21 de mayo de 2008 , en la que se establece la voluntariedad expresamente en la Exposición de motivos, incluyéndola también entre los principios de la mediación.

El efecto que pretende lograr la aplicación de los principios de voluntariedad y libre disposición del procedimiento de mediación, es que éste sea efectivo para la partes, de tal forma que se consiga una participación activa de las mismas en el procedimiento y una colaboración con el mediador, a los efectos de lograr que el procedimiento de mediación sea efectivo y pueda ponerse fin a la controversia existente.

Este principio lleva implícito el respeto de las partes a la decisión adoptada en el procedimiento de mediación, al que han acudido libre y voluntaria-

${ }^{41}$ Así la Ley de arbitraje señala que «las partes podrán convenir libremente el procedimiento al que se hayan de ajustar los árbitros en sus actuaciones» (artículo 25), «determinar libremente el lugar del arbitraje» (artículo 26) y su idioma (artículo 28). Estos aspectos han sido comentados por AlZAGA VILlAMIL, O. «Determinación del procedimiento». en Comentarios a la nueva ley de arbitraje, GonzÁlez SorIA, J.(coord), Aranzadi 2011 pp. 237 y ss.

${ }^{42}$ La Ley anterior 36/1988 hacía referencia expresa a la libertad de los ciudadanos como fundamento de la institución arbitral en su Exposición de Motivos e incentiva su utilización. Posiblemente la omisión a esta cuestión en la Ley 60/2003 se deba a que se ha dado por supuesto este fundamento del arbitraje en la libertad y no se ha entendido que sea necesario reiterarlo. Es opinión de Merino Merchán y Chillón Medina, oob cit. p. 100-101.

${ }^{43}$ El Tribunal Constitucional ha señalado en este sentido que la libertad es el fundamento y motor del arbitraje ATC 259/1993 y que la esencia de la institución arbitral como forma de exclusión de la vía judicial está en la autonomía de la libertad (STC 174/1995). 
mente e implica que cualquiera de ellas, pueda decidir, en cualquier momento, poner fin al procedimiento de mediación iniciado.

La norma se limita a establecer aquellos requisitos imprescindibles para dar validez al acuerdo que las partes puedan alcanzar, siempre bajo la premisa de que conseguir una solución pactada no es algo obligatorio, por así decir. De hecho, uno de los posibles objetivos de la mediación es simplemente mejorar las relaciones entre las partes en conflicto, sin buscar necesariamente un acuerdo de contenido concreto.

En este sentido, como ha señalado el Libro Verde sobre mediación, si el acuerdo final no reflejara la voluntad real de las partes, el compromiso efectivo que las partes están dispuestas a aceptar, con todo lo que eso implica de renuncia con relación a sus expectativas anteriores, el ADR no habría conseguido sus objetivos fundamentales, es decir, la verdadera solución del conflicto y la consiguiente pacificación social. En tal caso, señala el Libro Verde, habrá que temer nuevos problemas, como la impugnación jurídica de la validez del acuerdo, el cuestionamiento de la responsabilidad del tercero por «arrancarle» a una de las partes un compromiso no equitativo, etc. Por lo que conviene hacer todo lo posible para garantizar la validez de los consentimientos ${ }^{44}$.

Sin embargo, esta capacidad de disposición de las partes no es absoluta ni puede ser contraria a los principios, valores y derechos fundamentales inderogables, ni puede afectar al estricto derecho de la persona. Lo que supone que quedarán excluidas todas aquellas cuestiones que afectan de manera directa o indirecta al estatuto de la persona y a sus derechos fundamentales a los que se refieren los artículos 14 a $29 \mathrm{CE}$. De esta forma, el orden público viene a determinar las materias que quedan fuera de la disponibilidad de las partes y que por tanto no son susceptibles de ser sometidas a arbitraje $\mathrm{e}^{45}$ o mediación ${ }^{46}$.

${ }^{44}$ Libro Verde sobre las modalidades alternativas de solución de conflictos en el ámbito del derecho civil y mercantil fue elaborado por la Comisión Europea en el mes de abril de 2002. ob cit.

45 Merino Merchán JF y Chillón mediana, J.M ob cit. pp. 327 y ss. Se recogen las cuestiones a las que sería aplicable el criterio de indisponiblidad por razones de orden público: 1. Las normas constitucionales y de organización política, organización y funcionamiento judicial, así como las manifestaciones administrativas en las que el Estado aparece investido de autoridad ejerciendo potestades públicas y los derechos públicos subjetivos. 2. La cuestiones que definen el status de la persona: estado y capacidad de las personas, nacionalidad y condición de extranjeros, adopción, incapacidad, tutela, paternidad., etc. 3 . El régimen jurídicos de determinados actos y bienes como dominio público, naturaleza y transmisión de los bienes, etc. 4. Las restricciones a la libertad de comercio e industria o que limiten o alteren la libre competencia de los operadores del mercado, 5 . La relación estatutaria-funcionarial. 6. Los Tratados de la UE y demás normas y convenios y Tratados internacionales. 7 El Derecho Penal.

46 Sobre el ámbito de aplicación y materias disponibles en mediación vid. MARTín Diz, F. ob cit. . págs 87 y ss. Señala que son disponibles las que lo sean legalmente por las partes o bien que sean en su caso susceptibles de ser homologadas judicialmente. En el 
De otra parte, hay disposiciones legales, cláusulas compromisorias y resoluciones judiciales que imponen la mediación obligatoria como requisito necesario antes de la vía jurisdiccional ${ }^{47}$. Ello implica que la voluntariedad no se contradice con la posibilidad de obligar a las partes a acudir a una sesión informativa, o con la fijación de medidas que induzcan a demandar la mediación, siempre que no impidan el acceso a la tutela judicial ${ }^{48}$.

Por lo tanto, cuando existe un sometimiento expreso de las partes a la mediación, deberá intentarse antes esta, con carácter previo a la vía judicial o a otra vía extrajudicial. Así la Ley de Mediación en su artículo 6.2 hace referencia a esta posibilidad

«Cuando exista un pacto por escrito que exprese el compromiso de someter a mediación las controversias surgidas o que puedan surgir, se deberá intentar el procedimiento pactado de buena fe, antes de acudir a la jurisdicción o a otra solución extrajudicial. Dicha cláusula surtirá estos efectos incluso cuando la controversia verse sobre la validez o existencia del contrato en el que conste»

Hay que señalar, sobre el contenido de este precepto, que podría no tener mucho sentido obligar a alguien a participar en un procedimiento de mediación contra su voluntad, si el éxito del procedimiento depende, precisamente, de esta voluntad. Lo que la Ley pretende no es, sin embargo, la imposición forzosa del método mediador, sino que, una vez pactado, al menos se intente de buena fe, incluso a sabiendas de que una de las partes no desee hacerlo, pero como existió una cláusula firmada, la buena fe reclama al menos intentarlo, asumiendo que las partes pueden poner fin al procedimiento en cualquier momento ${ }^{49}$.

ámbito familiar quedarían excluidas las referentes a materia de capacidad de las personas y reconocimiento o impugnación de la filiación. En el ámbito penal rige, como sabemos, de manera general la garantía jurisdiccional del derecho penal. A su juicio, la introducción de la mediación penal en España podría requerir una modificación constitucional de las atribuciones que en materia de Justicia penal otorga la Constitución a jueces y magistrados con carácter de exclusividad (artículo 117.3 CE y 2.1 LOPJ). p. 91.

47 A este respecto, se ha señalado que éstas (y hace referencia a modo de ejemplo a la Ley argentina 24573 de 1995 , que introduce la mediación con carácter obligatorio previo a cualquier proceso, así como a la Sentencia de la AP de Baleares, 14 de enero de 2004, en que se remite a un procedimiento de mediación a los progenitores para someterse a un proceso psicológico) son inaceptables y de nulo valor jurídico porque contravienen el principio de voluntariedad que es esencial en la mediación. Ibidem.

${ }^{48}$ Ibidem. pp. 72 y ss. entiende que se conculca el derecho a la tutela judicial efectiva en lo que afecta al acceso a los órganos jurisdiccionales porque limita de manera injustificada y desproporcionada el acceso a tal derecho. Alude en ese sentido a la Directiva 93/13/CEE de 5 de abril, que considera abusivas la cláusulas que impongan la resolución de conflictos por mediación o cualquier otro medio extrajudicial.

${ }^{49} \mathrm{El}$ instrumento procesal del que dispone el demandado en estos casos para impedir el segundo proceso, es la llamada excepción de litispendencia, que debe ser alegada en la 
Por último, una vez tomado el acuerdo de acudir a un sistema de ADR, el artículo 39 de la LEC, establece que «el demandado podrá denunciar mediante declinatoria la falta de competencia internacional o la falta de jurisdicción por pertenecer el asunto a otro orden jurisdiccional o por haberse sometido a arbitraje o mediación la controversia.

\section{LA GARANTÍA DE LA TUTELA JUDICIAL EFECTIVA EN LOS PRINCIPIOS INFORMADORES DE LOS SISTEMAS DE ARBITRAJE Y MEDIACIÓN}

\subsection{Consideración general}

En un Estado de Derecho el control sobre la actividad de los ADRs es obligado como parte del contenido esencial del derecho a la tutela judicial efectiva sin que eso suponga una limitación en la voluntad de las partes, sino que debe entenderse, como aplicación de los principios constitucionales, que son comunes a cualquier procedimiento, independientemente de que se realice o no a través de la acción jurisdiccional, como son los principios de igualdad de las partes, audiencia, contradicción o la preservación del orden público que debe ir unida al contenido mismo del artículo $24 \mathrm{CE}^{50}$.

El derecho a la tutela judicial efectiva se refiere, como ha señalado el TC, a una potestad del Estado atribuida al poder judicial consistente en la prestación de la actividad jurisdiccional por Jueces y Tribunales, es decir, por los órganos jurisdiccionales del Estado integrados en el Poder judicial. Sin embargo, en el caso de los procedimientos alternativos, los ADRs, el Poder Judicial intervendrá, ya sea limitando los poderes del árbitro o mediador, o controlando que se han cumplido los principios básicos del procedimiento. Pero es determinante que frente al carácter universal de la tutela jurisdiccional del artículo 24.1, la intervención judicial se restringe a los supuestos tasados en la ley ${ }^{51}$, que se concibe como excepción a la prohibi-

contestación a la demanda y será examinada en la audiencia previa, en el juicio ordinario civil o en el acto de la vista en el juicio verbal (art. 416 y 443 LEC).En el artículo 443 LEC apartado tercero, establece en su último párrafo que «En atención al objeto del proceso, el tribunal podrá invitar a las partes a que se intente un acuerdo que ponga fin al proceso, en su caso, a través de un procedimiento de mediación, instándolas a que asistan a una sesión informativa...»

50 Vid. Martín Muñoz, A y Hierro Anibarro S. ob cit. pp. 38 y ss.

${ }^{51}$ BARONA VILAR S. entiende que no es un supuesto de numerus clausus. «En la misma Ley de arbitraje existen otros supuestos como la remoción de los árbitros, competencia judicial, que no se encuentra delimitada en el elenco de supuestos del artículo 8 sin que pueda negarse su eficacia y realidad. Otras cuestiones podrían discutirse pero hay que ofrecer soluciones a la posibilidad, por ejemplo, de impugnar las costas por indebidas o excesivas y no existiendo mecanismo especifico conformado para plantear esta 
ción general de intervención. De aquí que la actividad judicial se interprete de forma restrictiva ${ }^{52}$.

A su vez, forma parte de la regulación del artículo $24 \mathrm{CE}$ la protección frente a la Indefensión, que puede producirse cuando se sitúa a las partes en el proceso en una posición de desigualdad.

De esta forma, entendemos que la actuación que pone en relación al Poder Judicial con los árbitros y mediadores es tanto de asistencia como de control o fiscalización. La naturaleza de una y otra es bien distinta si bien algunas acciones pueden englobar ambas. La tutela judicial efectiva que obliga al Poder judicial, lo hace igualmente en relación a determinar las cuestiones que afectan en materia de ADR, y exceptuar las que son materia indisponible.

En cuanto a las acciones de asistencia, de obligada realización por el Poder Judicial, estarían por ejemplo la práctica de la prueba o el nombramiento de árbitros en los procedimientos arbitrales.

En el caso de la mediación, el poder judicial actúa como poder de homologación del acuerdo de mediación a solicitud de las partes, como juez de la ejecución y de las medidas cautelares que soliciten, en su caso, tras el acuerdo. Además ejerce una función fundamental en los supuestos de la «mediación intrajudicial» en los que actúa al inicio, como impulsor de la mediación. Adicionalmente, tanto en las mediaciones intrajudiciales como en las que no tienen esa naturaleza, el poder judicial desarrolla funciones concretas y fundamentales, como asegurar la protección de derechos de menores o incapacitados a lo largo del procedimiento.

Si bien la acción jurisdiccional es necesaria para el buen desarrollo del arbitraje y la mediación, el Tribunal Constitucional ha sido muy claro respecto de sus límites en la jurisprudencia que se ha dictado en relación con el arbitraje. Así, en STC 176/1966 señala en relación a una solicitud de amparo por vulneración del derecho a la tutela judicial efectiva una vez utilizada la vía de arbitraje, que

«el derecho a la tutela judicial efectiva no comprende el de obtener una decisión acorde con las pretensiones formuladas (STC 9/1981 y

pretensión, no queda mas posibilidad que entender abierta la intervención del juez y la aplicación de normas generales» en Comentarios a la Ley de arbitraje. (Ley 60/2003) BARONA VILAR, S. . (coord) Thomson-Civitas 2004. p. 70. Sobre el que la remoción no aparezca prevista en el artículo 8 de la Ley se ha entendido, GuZMÁn Fluja, V. Ob cit. pp. 242 y ss, que se trata de un lapsus del legislador que se salva mediante un mínimo esfuerzo interpretativo.

52 A esta cuestión hace referencia en el ámbito del arbitraje SEnEs Motilla, C. La intervención judicial en el arbitraje. Aranzadi, 2007 p. 24. Si bien, tanto el arbitraje como otros sistemas de ADRs, véase la mediación, se fundamentan en la misma base: la autonomía de la voluntad de las partes. En este sentido, ese carácter limitado y excepcional de la intervención de los jueces y tribunales en el procedimiento arbitral es igualmente aplicable a la mediación. 
52/1992, entre otras) ni ampara una determinada interpretación de las normas aplicables al caso (STC 33/1988) pero si a recibir una respuesta judicial a sus pretensiones, motivada y fundada en Derecho (STC 133/1989, 18/1990 y 11/1995, entre otras muchas) como ha ocurrido en este caso, no cabe estimar en modo alguno que el recurrente fuera privado de su derecho de acceso a la jurisdicción... tal planteamiento, sin embargo, no puede ser compartido, ya que supondría privar al arbitraje, cuya licitud constitucional hemos declarado reiteradamente (SSTC 43/1988, 15/1989,288/1993 y 174/1995) de su función como medio heterónomo de arreglo de controversias que se fundamenta en la autonomía de la voluntad de los sujetos privados: lo que constitucionalmente le vincula con la libertad como valor superior del ordenamiento (art. $1.1 \mathrm{CE}$ )》.

Si hay arbitraje sobre un asunto no puede haber jurisdicción y si hay proceso no puede haber arbitraje. Se trata por tanto de una exclusión de la jurisdicción que permite la denuncia mediante declinatoria de la falta de jurisdicción. Y no se trata de una cuestión de competencia, no se plantea un conflicto de competencia, sino que el convenio arbitral excluye la jurisdicción $^{53}$. El artículo 11 de la Ley de arbitraje señala que «1. El convenio arbitral obliga a las partes a cumplir lo estipulado e impide a los Tribunales conocer las controversias sometidas a arbitraje, siempre que la parte a quien interese lo invoque mediante declinatoria».

De otra parte, tenemos en cuenta que tanto en el ámbito del arbitraje como de la mediación, se han venido desarrollando instituciones específicas que surgen con el objeto de administrar los procedimientos de ADRs y de velar porque estos se desarrollen conforme a los principios comunes a cualquier proceso de forma que se asegure la legalidad y que se cumplan unos estándares mínimos necesarios para la validez de los sistemas de solución de conflictos.

\subsection{Arbitraje}

Son principios informadores de los procesos de arbitraje la igualdad, audiencia y contradicción, además del principio de confidencialidad ${ }^{54}$.

El artículo 24 de la Ley de arbitraje bajo el título «Principios de igualdad, audiencia y contradicción» señala: «1. Deberá tratarse a las partes con igualdad y darse a cada una de ellas suficiente oportunidad de hacer valer sus derechos». Este precepto es concreción del artículo $24 \mathrm{CE}$ y debe ser interpretado conforme al mismo.

${ }^{53}$ GuZmán Fluja, V. ob cit. pp. 471 y ss.

${ }^{54}$ Alzaga, O. señala en relación a este principio que su alcance se limita como consecuencia del artículo 120.1. CE que recoge el principio de publicidad. Se trata de una forma de garantía para el justiciable que es de aplicación al arbitraje con las limitaciones que resultan de la propia naturaleza del arbitraje. ob cit. p. 379. 
La igualdad, que engloba el principio de contradicción, exige que las partes en el proceso dispongan de iguales medios y oportunidades para su defensa, aunque no implica que cada parte deba tener un número igual de actos de alegación y prueba, sino que las posibilidades y oportunidades de las partes sean similares.

Las garantías de contradicción y audiencia evitan dictar una resolución sin que alguna de las partes haya podido influir en el resultado formulando alegaciones y presentando las pruebas que le convengan ${ }^{55}$. La garantía de igualdad, de una manera más general, es un mandato a los árbitros que no podrán conceder ningún privilegio o ventaja a ninguna de las partes en detrimento de la otra, y en ese sentido se configura como una limitación a la autonomía de la voluntad de las partes ${ }^{56}$.

El que las partes tengan «suficiente oportunidad de hacer valer sus derechos» debe entenderse como posibilidad de ejercitar los derechos de carácter procesal propios de la tutela judicial efectiva, tales como efectuar alegaciones, proponer prueba o que se lleve a cabo la práctica de la prueba admitida ${ }^{57}$. Lo determinante es que las partes puedan hacer valer sus derechos, sin que sea necesario que lo hagan de manera efectiva. De tal forma que, tal y como ha señalado el TC, no puede alegar indefensión con posterioridad quien hubiera podido evitarla de actuar de modo diligente (STC 211/89).

En lo que se refiere al procedimiento de arbitraje de una manera general, la ley actual señala en su artículo 7 «En los asuntos que se rijan por esta ley no intervendrá ningún tribunal, salvo en los casos en que ésta así lo disponga». De esta forma, la Ley está garantizando una mínima interferencia posible del juez estatal en el arbitraje.

A lo largo del proceso prima la autonomía de la voluntad y la ley se limita a establecer un régimen subsidiario para el caso de que las partes no hubieran

55 SÁnchez Pons, V. El control judicial en la ejecución del laudo arbitral. ThomsonAranzadi, 2009 p. 150 y ss. señala que si bien para algunos autores ambos vocablos son expresión de esa noción, otros distinguen entre audiencia, «nadie puede ser condenado sin ser oído y vencido en juicio» y el principio de contradicción entendido como el choque dialéctico de argumentos esgrimidos por las partes. Sin embargo, como señala DíEz PICAZO, L. «Principios de igualdad, audiencia y contradicción» en Comentarios a la nueva ley de arbitraje, GONZÁlEZ SoriA, J. (coord.) Aranzadi, 2011 pp. 370 y ss., las partes pueden optar porque no haya verdadera contradicción, con base en el principio dispositivo.

56 EsPada MÉndeZ, A. «Articulo 24. Principios de igualdad, audiencia y contradicción» en En Comentarios a la ley de arbitraje de 2003». Aranzadi, 2005, págs. 251 y ss.

${ }^{57}$ Ibidem págs. 254 y ss. Sobre por qué utiliza la expresión «suficiente» en lugar de «plena» entendemos que se trata de evitar posibles abusos de las partes para dilatar el procedimiento. Sin embargo, como este mismo autor señala, en los países en que se hace referencia a la «plena» oportunidad de las partes, así como en lo referente a la Ley Modelo, la plena oportunidad debe entenderse como razonable de forma que la eficiencia del arbitraje no se sacrifique por la actitud dilatoria de una de las partes. 
pactado nada al respecto. Así ocurre, por ejemplo, con las notificaciones, comunicaciones y cómputo de plazos, si bien la fijación por acuerdo de un régimen de notificaciones y comunicaciones no puede desconocer las exigencias del derecho de defensa, que se constituye en un límite infranqueable impuesto por el artículo $24 \mathrm{CE}$. Ello implica que las partes no pueden acordar un régimen de notificaciones mas severo para una de las partes o que es preciso garantizar que las partes tienen conocimiento de las actuaciones arbitrales ${ }^{58}$.

Además de la intervención judicial que tiene lugar al inicio y fin del procedimiento arbitral, está previsto que determinadas cuestiones se substancien de forma paralela al arbitraje, como la asistencia judicial en la práctica de la prueba o la adopción judicial de medidas cautelares, a las que hace referencia el artículo 8 de la Ley de arbitraje $2003^{59}$.

En relación con la asistencia judicial en la práctica de la prueba, los árbitros o cualquiera de las partes pueden solicitar el auxilio de los órganos jurisdiccionales en relación a las pruebas que no puedan efectuar por si mismos, conforme al artículo 33 de la Ley de arbitraje. Esta asistencia podrá consistir en la práctica de la prueba ante el tribunal competente o en la adopción por éste de medidas de aseguramiento, necesarias para que la prueba pueda ser practicada ante los árbitros.

Deberán ser las partes junto con el árbitro las que indiquen qué tipo de asistencia requieren, teniendo en cuenta que si optan por practicar la prueba ante el juez competente, es previsible que se demore y repercuta en el procedimiento arbitral ${ }^{60}$.

En lo que se refiere, en fin, a la adopción de medidas cautelares, hay prevista una competencia concurrente ya que los árbitros son competentes, de acuerdo con el artículo 23.1 de la Ley de arbitraje, para adoptar tales medidas. En este sentido, la Exposición de Motivos de la Ley de arbitraje señala:

«Los árbitros carecen de potestad ejecutiva, por lo que para la ejecución de las medidas cautelares será necesario recurrir a la autoridad judicial, en los mismos términos que si un laudo sobre el fondo se tratara.

${ }^{58}$ Guzman Fluja, v. ob cit. pp. 190 y ss. En relación a los actos de comunicación y notificación se deben tener en cuenta una serie de principios que son: 1. Regularidad Las notificaciones y comunicaciones deben efectuarse conforme al régimen legal aplicable. 2. Temporalidad. Que los actos sean recibidos con tiempo suficiente para que la parte pueda ejercer sus derechos. 3. Efectividad. Que suponga un conocimiento efectivo de la parte que lo recibe. 4. Eficiencia. Lograr que los actos de comunicación obtengan los máximos resultados en el menor tiempo posible, esto último se relaciona con la utilización de nuevas tecnologías.

59 Ibidem. págs. 242 y ss.

${ }^{60}$ Martín Alvarez, s. En Comentarios a la ley de arbitraje de 2003. ob cit. págs 311 y ss. PÉREZ-LlorCA, J. «Asistencia Judicial para la práctica de la prueba» en Comentarios a la nueva ley de arbitraje, GONZALEZ SORIA, J. (coord) Aranzadi, 2011 pp. 485 y ss., pp. 485 y ss. 
Sin embargo, si dentro de la actividad cautelar cabe distinguir entre una vertiente declarativa y una ejecutiva, esta ley le reconoce a los árbitros la primera, salvo acuerdo en contrario de las partes» ${ }^{61}$.

De nuevo se diferencia entre la competencia para declarar procedentes unas medidas cautelares solicitadas por las partes, que puede corresponder al árbitro o árbitros, y una competencia para la ejecución forzosa de las medidas declaradas procedentes, que solo corresponde y compete al poder judicial.

\subsection{Mediación}

Podemos entender que hay ciertos principios informadores de la mediación, que son de cumplimiento necesario, sin los cuales una mediación y su consecuente acuerdo serían nulos y vulnerarían las garantías propias de la tutela judicial efectiva. Tales principios están recogidos en la Ley 5/2012 y junto con la voluntariedad y libre disposición, a la que hemos hecho referencia, serían, además de la confidencialidad ${ }^{62}$, básicamente la igualdad entre las partes y la neutralidad ${ }^{63}$.

A la igualdad entre las partes, la Ley hace referencia junto con el principio de imparcialidad del mediador. El procedimiento de mediación debe garantizar que las partes intervengan con plena igualdad de oportunidades, manteniendo el equilibrio entre sus posiciones y el respeto hacia los puntos de vista por ellas expresados, y que puedan llegar por sí mismas a un acuerdo, no pudiendo el mediador actuar en interés o en perjuicio de ninguna de ellas.

61 Vid. Senes Montilla, c, ob cit. pág. 75 y ss.

${ }^{62}$ Este principio asegura la mayor confianza de las partes y contribuye a un mejor desarrollo del proceso. El principio de confidencialidad es aplicable como un equivalente a reserva sobre la información obtenida a lo largo del procedimiento. Esta obligación incluye la de no revelar ningún dato del que se haya tenido conocimiento a través de la mediación, durante la misma y una vez ésta haya finalizado con o sin acuerdo. Se refiere al mediador, a las instituciones de mediación y a las partes intervinientes. No rige en aquellas mediaciones o cuestiones respecto de las cuales las partes expresamente lo acuerden así, y tampoco en aquéllas donde la mediación sea pública porque la ley lo exija.

${ }^{63}$ Destacamos la buena fe, como un elemento fundamental para la resolución o interpretación del conflicto y la superación de la desconfianza, incluso si no se llega a acuerdos. Así como otros principios, no menos importantes, que están en alguna regulación autonómica, como el de protección a los menores, a los discapacitados y a las personas mayores, previsto en las LMF Madrid, Castilla-León y Andalucía. También la legislación gallega habla del bienestar y el interés superior del menor. Y es interesante el artículo 10 LMF País Vasco, que identifica diez principios: (a) voluntariedad; (b) confidencialidad; (c) transparencia; (d) respeto al Derecho; (e) imparcialidad; (f) neutralidad; (g) flexibilidad; (h) debate contradictorio; (i) inmediatez; (j) buena fe, colaboración y mantenimiento del respeto entre las partes. En Derecho comparado muestra que los ordenamientos también incluyen otros principios, como los de transparencia, flexibilidad, oportunidad o el principio de economía procesal. Libro Blanco de Mediación. 
De esta forma, una posición dominante o la existencia de cualquier traza de violencia, amenaza o intimidación impide que se celebre una mediación. De ahí que podamos entender que no es posible la mediación en casos de violencia de género, precisamente porque se rompe el principio de igualdad entre las partes ${ }^{64}$.

A estos efectos, la Ley 5/2012 contempla la obligación del mediador de no iniciar o abandonar la mediación cuando concurran circunstancias que afecten a su imparcialidad, así como revelar cualquier circunstancia que pudiera afectarle a la hora de conducir el proceso con imparcialidad.

Un paso mas allá supondría que el mediador deba incluso, como señala el Código de conducta europeo para mediadores ${ }^{65}$, no solo actuar imparcialmente con las partes en todo momento, sino también esforzarse en demostrar su imparcialidad.

Junto con la imparcialidad, el principio de neutralidad trata de resaltar que la solución por vía de mediación sólo puede llegar a través de un acuerdo voluntariamente consentido por ambas partes, por si mismas, sin que el mediador esté facultado para decidir ni pueda imponer a las partes ninguna clase de solución o medida concreta.

Ambos principios están muy relacionados, si bien podemos entender que la diferencia entre ambos reside en que el mediador es imparcial en sus relaciones con las partes y neutral con respecto al resultado de la mediación. Es propio únicamente de la mediación, no de otro tipo de sistemas, como el arbitraje.

Este principio no sólo implica que la mediación es una figura autocompositiva, sino que los valores, criterios y posibles soluciones que el mediador tiene ante los problemas que se le presentan no han de condicionar la decisión a que lleguen las partes, siendo estas las únicas facultadas para alcanzar una solución sobre la controversia existente.

Este principio de neutralidad implica, por último, no solo una actuación negativa, en el sentido de no tomar partido, sino que va mas allá, tratando de situar a las partes en una posición equilibrada desde la que defender sus intereses.

\section{LA FUNCIÓN DEL PODER JUDICIAL COMO GARANTE Y EJECUTOR DE LAUDOS Y ACUERDOS DE MEDIACIÓN}

Vemos a continuación dos cuestiones que ponen en relación al Poder Judicial con los laudos y acuerdos de mediación respectivamente. La anulación de los mismos y su ejecución forzosa.

${ }^{64}$ Seguimos en este punto a MARTIN DIZ, F. ob cit. págs 395 y ss.

${ }^{65}$ El Código de conducta europeo para mediadores fue aprobado en julio de 2004. Puede verse en ec.europa.eu/civiljustice/adr/adr_ec_code_conduct_es.pdf 
Respecto de la anulación, la Ley prevé anular el laudo, así como el convenio de mediación en determinados casos y por ciertos motivos.

Antes de concretar los motivos de anulación, tengamos en cuenta que la decisión del árbitro es ejecutiva en sí misma. El convenio de mediación, si se quiere convertir en título ejecutivo, debe elevarse a escritura pública. Es decir, su efectividad es la propia de un convenio entre partes privadas documentado públicamente en forma de escritura de esa naturaleza.

La anulación del laudo se concibe como un proceso especial que debe fundamentarse en alguno de los motivos que establece la Ley ${ }^{66}$. No es comparable con una segunda instancia, por lo que no permite, salvo que haga referencia a la vulneración del orden público, entrar en el fondo del asunto, de manera que su carácter es, como ha señalado el Tribunal Constitucional, limitado, formal y externo (STC 43/1988) .

Su objeto es, como ha señalado el TC (ATC 259/1993).

"garantizar que el nacimiento, desarrollo y conclusión del procedimiento arbitral se ha ajustado a lo establecido en la ley, pretendiéndose, con ello, que la cesión a un particular de la función de resolver un conflicto, y el ejercicio de esa función, se lleve a cabo dentro de las coordenadas legales, con sujeción a los principios jurídicos ínsitos en el ordenamiento procesal y exigibles en el ámbito de la tutela judicial efectiva».

Esta posibilidad de ejercitar la acción de anulación de un laudo definitivo, se basa en la protección del derecho a la tutela judicial efectiva mediante el control del laudo y de forma indirecta de las actuaciones arbitrales, para lo cual hace referencia a los siguientes motivos concretos y al genérico de orden público ${ }^{67}$.

«1) Que el convenio arbitral no existe o no es válido ${ }^{68}$. 2) Que no ha sido debidamente notificada de la designación de un árbitro o de las actuaciones arbitrales o no ha podido, por cualquier otra razón, hacer valer

${ }^{66}$ Álvarez SÁNCHEZ DE Movellán. «Algunas cuestiones sobre la anulación judicial del laudo en la Ley 60/2003, de Arbitraje» La Ley.

${ }^{67}$ Sobre este tema puede verse: Álvarez SÁnchez, Pl. La anulación del laudo arbitral. El proceso arbitral y su impugnación. Comares, Granada, 1996. GonZÁLEZ-MonTES, J.L. El control judicial del arbitraje. La Ley. Madrid, 2008 . Senes Motilla, C. ob cit. HinOJOSA, R. «El control del laudo: acciones de anulación y de revisión» en Merchán. J.F. Curso de derecho arbitral. Tirant Lo Blanch, Valencia 2009.

${ }^{68} \mathrm{La}$ invalidez en el fondo sería equivalente a una nulidad absoluta, y en ese sentido responde a la misma categoría que la inexistencia. Por sí misma la invalidez es consecuencia de la ausencia de los elementos esenciales del convenio: consentimiento, objeto y causa. En caso de que se entienda, como lo hace CARDASU PALAU, J. «Motivos» en Comentarios a la nueva ley de arbitraje González SoriA, J.G. (coord) Aranzadi, 2011 p. 556, que la forma es requisito de validez, también deberá ser entendido éste como elemento esencial del que depende la validez del convenio. Además de supuestos de caducidad por agotamiento o pérdida de vigencia. De manera general podemos decir que el 
sus derechos ${ }^{69}$. 3) Que los árbitros han resuelto sobre cuestiones no sometidas a su decisión ${ }^{70}$. 4) Que la designación de los árbitros o el procedimiento arbitral no se han ajustado al acuerdo entre las partes, salvo que dicho acuerdo fuera contrario a una norma imperativa de esta Ley, o, a falta de dicho acuerdo, que no se han ajustado a esta ley ${ }^{71}$. 5) Que los árbitros han resuelto sobre cuestiones no susceptibles de arbitraje ${ }^{72}$. 6) Que el laudo es contrario al orden público ${ }^{73} \gg$.

Por último, en lo que se refiere a la impugnación del laudo y el posible ámbito de actuación del Tribunal Constitucional, vemos que en STC 9/2005 señala «Conforme a nuestra reiterada jurisprudencia el laudo arbitral no puede ser objeto directo de impugnación por medio del recurso de amparo ya que este Tribunal carece de jurisdicción para enjuiciar el laudo arbitral en sí mismo considerado». De esta forma, la actuación del Tribunal Constitucional, tal y como señala la sentencia citada, solo en los casos en que «las supuestas vulneraciones alegadas sean referibles a la actuación del órgano jurisdiccional que conoció del recurso frente al laudo, estará justificado que este Tribunal enjuicie una eventual lesión del derecho a la tutela judicial efectiva».

Por lo tanto, el Tribunal Constitucional no viene ejercitando un control sobre los laudos por vía de recurso de amparo salvo que se den dos condiciones: 1. Que se produzca una violación de un derecho fundamental con relevancia constitucional en sede arbitral siempre que tal infracción se haya advertido en la sede por aquel que se ha visto vulnerado en su derecho y 2 . que tal violación no se haya reparado por las AAPP en el proceso de acción de

convenio, además de existir, debe cumplir con los requisitos a que hace referencia la Ley de arbitraje y el Código Civil . según el mismo autor en págs 553 y ss.

${ }^{69}$ Del cumplimiento de esta obligación en materia de notificaciones, deriva la de hacer valer en el arbitraje los principios de igualdad, audiencia y contradicción de las partes.

${ }^{70} \mathrm{Se}$ incluye con este motivo la exigencia de congruencia en el proceso de arbitraje. En caso de que se aceptara la impugnación por este motivo, debemos entender que la misma afectaría solo a aquellos aspectos no sometidos a la decisión del árbitro siempre que puedan separarse de las demás.

${ }_{71}$ En este punto debemos tener en cuenta que el principio de autonomía de las partes determinará quienes sean el arbitro o árbitros, con las salvedades de normas que fueran de obligado cumplimiento. Como pueda ser que fueran nombrados árbitros que sean personas jurídicas o que no estén en pleno ejercicio de sus derechos civiles. HinOJOSA, R. ob cit.

${ }_{72}$ Se trata de que el orden público determina que quedarán excluidas todas aquellas cuestiones que afectan de manera directa o indirecta al estatuto de la persona y a sus derechos fundamentales a los que se refieren los artículos 14 a $29 \mathrm{CE}$.

${ }^{73}$ Estamos ante un límite al principio dispositivo de las partes en el procedimiento arbitral impreciso y difícil de concretar y definir, ya que la noción de orden público es difusa y su contenido varia en función de distintos criterios. Si bien debe estar en relación con los derechos fundamentales y libertades públicas constitucionalmente garantizados, especialmente en este tema con la tutela judicial efectiva. 
anulación del laudo siempre que haya también sido puesta de manifiesto dicha vulneración ${ }^{74}$.

En lo que se refiere al acuerdo de mediación, -total o parcial-, tiene carácter vinculante, del que las partes pueden instar su elevación a escritura pública al objeto de configurar tal acuerdo como un título ejecutivo.

Sobre la cuestión de en qué casos es posible ejercitar la acción de nulidad del acuerdo, ésta sólo podrá ejercitarse por las causas que invalidan los contratos $^{75}$. Por lo que, en general, hay que señalar que no se aprobarán aquellos acuerdos que resulten contrarios a derecho, contravengan la moral, las disposiciones de orden público, afecten a derechos irrenunciables o de terceros o vulneren el principio de equidad en perjuicio de una de las partes.

La segunda de las cuestiones que afecten a la jurisdicción ordinaria con los sistemas arbitrales y de mediación es la ejecución. En todo caso, la ejecución forzosa de las decisiones arbitrales y de los convenios de mediación es competencia exclusiva e indelegable de los tribunales de Justicia. Si esta conexión no existe, tales procesos no tienen mas que un valor testimonial. Es por tanto preciso asegurar esa conexión y para ello la legislación debe ser muy clara y la práctica judicial facilitar con su actuación la ejecución de los títulos resultantes de los procedimientos de arbitraje y mediación ${ }^{76}$.

Por tanto estamos ante el ejercicio del derecho a la tutela judicial efectiva en su vertiente ejecutiva. El Tribunal Constitucional ha considerado que la acción ejecutiva forma parte del derecho a la tutela judicial efectiva, de forma que resulta contrario al artículo $24 \mathrm{CE}$ la inejecución de la sentencia en sus propios términos (STC 189/1990).

Tanto los laudos como los acuerdos de mediación son títulos ejecutivos extrajudiciales, a los que corresponde un procedimiento ordinario de ejecución singular en el que el control que se realiza de los laudos y acuerdos de mediación es similar al que se lleva a cabo para la ejecución de una sentencia. Esto es, que concurran los requisitos procesales y que sean conformes con la naturaleza y contenido del título.

${ }^{74}$ Merchán, J.F Curso de derecho arbitral. Tirant Lo Blanch, Valencia 2009 p. 33.

${ }^{75}$ Los requisitos de los contratos, la validez de los mismos, las causas de nulidad, eficacia, interpretación etc., se regulan en los artículos 1254 y siguientes del Código Civil. En cuanto al consentimiento, el artículo 1265 del Código Civil regula las causas de nulidad del consentimiento. Por lo que respecta al objeto de los contratos nos referimos al artículo 1271 del Código Civil, Por lo que respecta a la causa de los contratos, los artículos 1274 a 1277 del Código Civil. En cuanto a la acción de nulidad se regula en los artículos 1301 y siguientes del Código Civil. Se establece un plazo de duración de la acción de nulidad de cuatro años.

${ }^{76} \mathrm{Si}$ bien es en alguna medida cierto, que por la naturaleza de la mediación la ejecución forzosa del acuerdo contradice el fundamento mismo de la mediación. BARONA, S. Mediación... ob cit. pp. 503 y ss. 
Como sabemos, el proceso de ejecución está destinado a la realización judicial del derecho del acreedor reconocido en un título que puede ser una sentencia firme, un laudo arbitral, una escritura pública o cualquiera de los títulos que según el artículo 517 LEC, lleva aparejada la ejecución.

En concreto, el artículo 517.2 LEC establece que los títulos ejecutivos que llevan aparejada ejecución son; entre otros, las sentencias firmes, los laudos o resoluciones arbitrales y los acuerdos de mediación, debiendo estos últimos haber sido elevados a escritura pública de acuerdo con la Ley de mediación en asuntos civiles y mercantiles.

En lo que se refiere al arbitraje, ya la Ley $36 / 88$ le dota de los mecanismos suficientes para que los laudos produzcan efectos de cosa juzgada, lo que supuso un efecto determinante a la hora de que los ciudadanos pudieran utilizar esta vía con seguridad ${ }^{77}$. El efecto de cosa juzgada, se debe entender en un doble sentido, formal y material.

En un sentido formal la cosa juzgada sería el estado jurídico en que se encuentra un asunto que ha sido objeto de un procedimiento. $Y$ en un sentido material se entiende como el efecto de la firmeza sobre el fondo que conlleva vinculación de los órganos jurisdiccionales respecto del contenido ${ }^{78}$.

En el ámbito jurisdiccional, la idea de firmeza o sentencia definitiva tiene varias acepciones. Puede entenderse en el sentido de sentencia que pone fin al proceso o a las resoluciones que recaen sobre un incidente, o bien contrapuesta a la sentencia incidental o referida a cualquier resolución judicial. Pueden también referirse a la firmeza de una sentencia que la hace irrevocable, en el sentido de que la revocación solo es posible a instancia de las partes a través de un recurso si éste es estimado ${ }^{79}$.

Trasladada la idea de firmeza de la sentencia a un laudo podemos entender que un laudo definitivo es irrevocable por parte del órgano que dictó la resolución y en tanto que vincula de la misma forma que una sentencia ${ }^{80}$.

Aunque suelan coincidir, sin embargo, cosa juzgada y firmeza no son el presupuesto del efecto ejecutivo de una sentencia o un laudo ya que cabe, entre otras cosas, la ejecución provisional. Lo determinante a efectos de eficacia ejecutiva en un laudo es que revista la condición de título ejecutivo ${ }^{81}$.

Serían título ejecutivo los laudos definitivos, que resuelven el fondo del asunto, los laudos parciales y las decisiones de los árbitros que éstos pueden

77 Entre otros vid, Almagro Nosete, J.. (1987) «La ejecución del laudo arbitral» Revista Universitaria de Derecho Procesal. núm. 0. 1987.

78 Ormazabal Sánchez, G. La ejecución de los laudos arbitrales. Bosch 1996. pp. 41 y ss.

79 Ibidem pp. 44 y ss.

${ }^{80}$ Sobre este tema vid, entre otros, Sánchez Pons, V. ob cit.. Ormazabal Sánchez, G. $o b$ cit.

${ }^{81}$ Ormazabal SÁnchez, G. ob cit. 
dictar acordando medidas cautelares. Y solo serían títulos ejecutivos los laudos de condena, aquellos que contienen de forma principal una orden al condenado y no los que fueran de naturaleza declarativa o constitutiva ${ }^{82}$.

En el procedimiento de arbitraje, hasta la Ley 60/2003 es preciso protocolizar el laudo ante notario. Es con esta ley y su intención de evitar formalismos que no se utilizan en el derecho comparado ni a los que se hace referencia en los Tratados Internacionales, que desaparece la obligación de la ley anterior de protocolizarlo.

La ley 60/2003 señala en su artículo 43 que el laudo firme produce efectos de cosa juzgada. El carácter ejecutivo del laudo lo equipara a una sentencia pero precisando de la acción de los órganos jurisdiccionales para su ejecución. En este punto se hace mas clara la relación entre la institución arbitral y el Poder Judicial y se pone de manifiesto el contenido de la LOPJ artículo 2,21 y 22) y la Ley 46/2003, en desarrollo del artículo $117 \mathrm{CE}$, de acuerdo con los que la capacidad para ejecutar lo juzgado corresponde exclusivamente a los juzgados y tribunales.

Nos preguntamos acerca de cuales son las posibilidades y límites a la capacidad de control de los jueces en el momento de la ejecución del laudo y cual es su fundamento.

Partimos de que el control regular del procedimiento corresponde inicialmente a las partes, que pueden oponer las excepciones que consideren a lo largo del procedimiento, y al propio árbitro, que las puede apreciar. Y una vez emitido el laudo, se puede ejercer la acción de anulación del mismo. Por lo tanto, debemos entender que el propio proceso arbitral incluye los mecanismos de garantía de la tutela judicial efectiva que deben ser ejercitados por las partes ${ }^{83}$.

De esta forma, al tener el laudo efecto de cosa juzgada, el arbitraje se interna en el ámbito jurisdiccional, de ahí que con fundamento en el artículo 24 CE la Ley de arbitraje prevé la acción de anulación del laudo en su artículo 40. Tal acción viene, por tanto, a sumarse a las garantías de la tutela judicial efectiva en el procedimiento arbitral ${ }^{84}$

En el caso de la mediación, la ley 5/2012, señala en su artículo 25.2:

«Para llevar a cabo la elevación a escritura pública del acuerdo de mediación, el notario verificará el cumplimiento de los requisitos exigidos por la Ley y que su contenido no es contrario a Derecho».

La ley ha obligado a la elevación a escritura pública como paso necesario para su consideración de título ejecutivo. Podría no haber sido necesario, de

${ }^{82}$ Fernandez-Ballesteros, MA. «Normas aplicables» en Comentarios a la nueva ley de arbitraje, Gonzalez Soria, J. (coord) Aranzadi, 2011 págs 633 y ss.

${ }^{83}$ SÁnchez Pons, V. ob cit. pp. 24-25.

${ }^{84}$ Goullant Santurtun, A. En «Comentarios a la ley de arbitraje de 2003». ob cit. pp. 383 y ss. 
la misma forma que hoy no es exigible que los laudos arbitrales se protocoli$\operatorname{cen}^{85}$. Pero esta diferencia deriva de la distinta naturaleza de los institutos en cuestión: en el arbitraje las partes someten y aceptan la decisión de un tercero; en la mediación son ellas, y solo ellas, las que alcanzan el acuerdo, de modo que su decisión asume naturaleza contractual o convencional, y de ahí la exigencia de protocolización para alcanzar la consideración procesal de titulo ejecutivo.

De esta forma, el procedimiento de ejecución de los acuerdos, se prevé que se ajuste a las previsiones que ya existen en el Derecho español y sin establecer diferencias con el régimen de ejecución de los acuerdos de mediación transfronterizos cuyo cumplimiento haya de producirse en otro Estado; para ello se requerirá su elevación a escritura pública como condición necesaria para su consideración como título ejecutivo. Además de la opción de crear el título ejecutivo gracias a la actuación del notario, el acuerdo puede ser homologado por el juez ${ }^{86}$.

Sin embargo, como se ha señalado, respecto de los acuerdos no jurisdiccionales que no reúnan los caracteres para ser títulos ejecutivos, quienes han otorgado el pacto deben hacerlo valer mediante un proceso declarativo. De tal forma que, en realidad, lo ejecutivo no es el acuerdo sino la sentencia por la que se ha condenado al cumplimiento del pacto ${ }^{87}$.

\section{SÍNTESIS Y CONCLUSIONES}

Después del análisis que hemos efectuado, podemos sintetizar las conclusiones que alcanzamos en el presente trabajo del modo siguiente:

1. En toda sociedad existe la realidad del conflicto, en enfrentamiento o debate entre sujetos. Es misión del Estado que dicho conflicto se resuelva y ejecute conforme a las normas del Derecho establecido como tal por el propio Estado.

2. En todo conflicto existen dos fases diferenciales. La solución, esto es, la definición de a quien corresponde la razón en el conflicto, y la ejecución forzosa de la solución adoptada. Esta última siempre y en todo caso corresponde en monopolio al Estado a través de la función jurisdiccional, de modo que la atribución constitucional del monopo-

${ }^{85}$ En Ecuador, en la reciente reforma de la Ley de Arbitraje y Mediación, el articulo 47 de la misma señala que «el acta de mediación en que conste el acuerdo tiene efecto de sentencia ejecutoriada y cosa juzgada y se ejecutará del mismo modo que las sentencias de última instancia siguiendo la vía de apremio».

${ }^{86}$ En este caso la ley no innova puesto que la posibilidad de dar fuerza ejecutiva a un acuerdo sobre el que existía un conflicto ya está prevista en la LECiv tal y como señala Bonet Navarro A. Proceso Civil y Mediación, Aranzadi, 2013. p. 25.

87 Ibid. págs. 153 y ss. 
lio jurisdiccional en cuanto se refiere a «haciendo ejecutar lo juzgado» no se altera por la aparición de los ADRs. El Estado no puede delegar en particulares el ejercicio de la violencia legal sobre los individuos, de modo que esa violencia legal solo puede ejercerse a través de Tribunales.

3. En consecuencia, el ámbito propio de los ADRs es la solución a un conflicto que reúna dos condiciones: se genere entre particulares, personas físicas o jurídicas privadas, y se trate de materia disponible. El primer requisito impone que la presencia del Estado o Administraciones Públicas como uno de los elementos subjetivos del conflicto excluye la posibilidad -al menos al día de hoy- de solución al conflicto al margen del poder judicial. El segundo requisito reclama que el conflicto verse sobre materia disponible, que pertenezca al ámbito del poder de decisión de los particulares, y que por tanto no se puede incurrir en el difícil y mutante concepto de materia de Orden Público.

4. La solución del conflicto, en todo caso, requiere una actuación previa de parte dirigida a lograr dicha solución. Esto opera siempre, incluso en el orden penal, puesto que rigiendo el principio acusatorio, no basta con la apariencia de violación de norma sino que, además, es necesario una actuación de parte, sea Ministerio Fiscal, acusador popular o acción popular para que pueda ejercerse la función jurisdiccional incluso en este ámbito penal especialmente grave. Por tanto, en el campo extra penal, tanto la Justicia, en sentido estricto, la función jurisdiccional, como los ADRs, funcionan siempre que medie previamente una decisión voluntaria de alguna o de ambas partes en el conflicto.

5. Precisamente por ello el inicio del arbitraje debe contar con una cláusula de sometimiento a este sistema de $\mathrm{ADR}$, cláusula que debe nacer de la libre voluntad de las partes. Al igual sucede en el sistema de mediación, de modo que solo la decisión de las partes de aceptar la intervención de mediador puede legitimar la existencia misma del procedimiento. Ambos ADRs nacen sustentados en la decisión libre de las partes de querer esa fórmula de solución de su conflicto.

6. El arbitraje se asemeja a la función jurisdiccional en el sentido de que las partes entregan a un tercero la solución del conflicto. De este modo, es el tercero -árbitro- quien decide y con carácter forzoso. Una vez firmada la cláusula arbitral una de las partes no pude liberarse de ella, de modo que la otra parte puede, no solo conseguir de los jueces y tribunales la designación de árbitro, en su caso, sino además, que se imponga a la otra parte la solución al conflicto proporcionada por el árbitro.

7. La mediación participa sustancialmente de la naturaleza del contrato o convenio inter privados puesto que el mediador no soluciona, no 
adopta decisión alguna sobre la mejor solución del conflicto, sino que simplemente canaliza el debate de manera ordenada y conforme a los principios de la buena fe para tratar de conseguir que las partes solucionen el conflicto. De forma gráfica podríamos decir que las partes en la mediación son árbitros de si mismos y la fuerza de su decisión deriva de su propia voluntad expresada en convenio escrito.

8. El arbitraje, al atribuir a tercero la decisión, reclama un procedimiento aunque flexible, sometido a los principios básicos del proceso civil. El procedimiento de mediación, dentro de los amplísimos cauces que establece la ley, se sujeta de modo soberano a la decisión de las partes. Por ello, en el caso de las decisiones de mediación, la ley establece que el convenio firmado entre las partes que da solución al conflicto, puede ser atacado por las mismas causas que permiten atacar la validez de los contratos, lo que indica a las claras la naturaleza contractual que la ley atribuye a la solución acordada entre partes, como no podía ser de otro modo.

9. No obstante, la mediación conecta con el procedimiento judicial de dos modos. a) En la mediación «sugerida» por el propio órgano jurisdiccional cuando existe un procedimiento en marcha. $\mathrm{y} b$ ) mediante la atribución de efectos judiciales a la mediación acordada, pudiendo una parte solicitar la inactividad judicial por medio de declinatoria mientras no se resuelve, en un sentido u otro, la mediación en marcha, y dotando la Ley de eficacia suspensiva de la prescripción y caducidad a los acuerdos de inicio y pendencia del procedimiento de mediación.

10. La decisión del árbitro es ejecutiva en si misma. El convenio de partes en el caso de la mediación, si se quiere convertir en título ejecutivo, debe elevarse a escritura pública. Es decir, su efectividad es la propia de un convenio entre partes privadas documentado públicamente en forma de escritura de esa naturaleza.

11. En todo caso, la ejecución forzosa de las decisiones arbitrales y de los convenios de mediación es competencia exclusiva e indelegable de los tribunales de Justicia.

TITLE: The guarantee of the right to effective judicial protection in the major systems of alternative conflict resolution: arbitration and mediation

RESUMEN: En este artículo se trata de delimitar el papel del Estado como garante de los derechos fundamentales en los casos en que la Justicia no se administre directamente por los órganos del Poder Judicial, sino mediante la utilización de sistemas alternativos de resolución de conflictos. Se analizan las acciones concretas que deben someterse al control propiamente jurisdiccional, para que, respetando el principio dispositivo en 
los conflictos entre particulares sobre materias que no afectan a la noción de orden público, la elección de las vías alternativas no conlleve demolición del inderogable principio de Tutela Judicial Efectiva. Ello nos conduce a delimitar los principios informadores de los principales sistemas alternativos, así como el control y ejecución de los laudos arbitrales y acuerdos de mediación.

PALABRAS CLAVE: Arbitraje, mediación, tutela judicial efectiva.

ABSTRACT: This article analyses the role of the State as guarantor of fundamental rights in cases where justice is not administered directly by the organs of the judiciary, but through alternative dispute resolution systems. The article reviews the specific actions that must be subject to jurisdictional control so that, respecting the principle of parties' disposition for disputes which subject-matter does not relate to public policy, the choice of alternative dispute resolution mechanisms does not entail the defeat of the mandatory principle of judicial effective protection. This leads us to define the reporting principles underpinning the main alternative dispute resolution systems as well as monitoring and enforcement of arbitral awards and mediation agreements.

KEY WORDS: Arbitration, Mediation, Effective Judicial Protection.

RECIBIDO: 22 mayo 2014 ACEPTADO: 26 mayo 2014 